\title{
A study of hearing improvement after myringoplasties in Bir Hospital, Kathmandu
}

\author{
L.K. Yadav ${ }^{1}$, D. Shrestha ${ }^{2}$, J. Pradhananga ${ }^{3}$ \\ ${ }^{1}$ Senior Consultant ENT, Head and Neck Surgeon, ${ }^{2}$ Asst. Professor, ${ }^{3}$ Medical Officer, Dept. of ENT, Bir Hospital, NAMS, \\ Kathmandu, Nepal
}

\begin{abstract}
Myringoplasty is one of the most common ear surgery performed for chronic suppurative otitis media tubo tympanic type. The prime concern for patients who are willing to undergo myringoplasty is hearing improvement. The aim of this study is to assess the improvement of hearing after myringoplasties for Chronic Suppurative Otitis Media tubo tympanic type. The total number of patients included in the study was 105. Myringoplasties were performed in 129 patients, and only those who had graft uptake i.e. 105, were selected for the study. Age of the patients varied from 13 to 45 years. Pure tone audiogram was done before the operation and four weeks after the operation, and air conduction thresholds were compared. It was found that $83 \%$ of the patients had some degree of hearing improvement after the operation. No significant complications were observed except that few patients complained of pain at the site of incision for harvesting the graft. Thus, this study shows that, patients can be assured that the chances of hearing improvement is acceptable and can undergo the operation without fearing complications.
\end{abstract}

Keywords: Chronic suppurative otitis media, tubo tympanic type, graft, hearing improvement, myringoplasty.

\section{Introduction}

Hearing improvement is one of the objectives of myringoplasty, though all the patients undergoing this operation do not achieve this goal. Most of the people are concerned about hearing improvement after the operation. Myringoplasty is the repair of the tympanic membrane perforation. It improves hearing by two mechanisms. First, closure of the tympanic membrane perforation restores the vibratory area of the membrane and second, it affords round window protection. ${ }^{1}$ The history of

Correspondence: L.K. Yadav

E-mail: lalkydv@hotmail.com closure of the tympanic membrane perforation to improve hearing dates back to the $16^{\text {th }}$ century, using various material like prosthesis (thin rubber disk, used by Toynbee), pig's bladder membrane, skin, vein etc. The success rate with these materials were however low. Ultimately, the temporalis fascia graft was used to close the perforation during the 1950's and with this the best take rates were reported to be about 70 to $90 \% .^{2}$ The higher percentage of graft uptake popularized myringoplasties as the method of improving hearing. In a country like Nepal, where many people especially in remote and rural areas suffer from 
Journal of College of Medical Sciences-Nepal,2010, Vol-6,No-4

hearing loss due to Chronic Suppurative Otitis Media, tubo tympanic type, myringoplasty will prove to be a surgery to improve hearing which is both cost effective and less time consuming.

\section{Materials and methods}

This study was carried out in the department of ENT, Bir hospital. Out of the 129 patients who underwent myringoplasty, between May 2008 to May 2010, those who had graft uptake were selected for the study. The total number of patients selected for the study was 105 . All these patients got an audiogram done before surgery. Then the patients underwent myringoplasty either under general or local anesthesia. General anesthesia was used for those under 15 years of age and in apprehensive patients. An Olympus operating microscope was used for the surgery. The surgeries were performed using temporalis fascia graft, with underlay technique and via per meatal route. The average duration of surgery was 75 minutes. All the operations were performed by the same surgeon. The patients were followed up at one week for stitch and ear pack removal. The patients were again followed up after four weeks for post operative audiogram. The pure tone average was based on hearing levels at $0.5,1.0$ and $2.0 \mathrm{kHz}$. The mean improvement in air conduction was the difference between pre-operative and post-operative values. The pre operative and post operative audiogram were compared and hearing improvement assessed.

\section{Results}

The age of the patients in this study varied from 13 to 45 years. The majority of patients were in the group 21 - 30 years (46\%), followed by $11-20$ years (34\%), $31-40$ years (12\%), $41-50$ years $(8 \%)$. (Table 1) The male to female ratio was 1:1.23. The maximum conductive hearing loss noted before the operation was $55 \mathrm{~dB}$, likewise the minimum conductive hearing loss noted was $36 \mathrm{~dB}$.

Table 1: Age and sex wise distribution

\begin{tabular}{lccc}
\hline $\begin{array}{l}\text { Age group } \\
\text { (years) }\end{array}$ & Male & Female & Total \\
\hline $11-20$ & 20 & 16 & 36 \\
$21-30$ & 19 & 29 & 48 \\
$31-40$ & 5 & 8 & 13 \\
$41-50$ & 3 & 5 & 8 \\
Total & 47 & 58 & 105 \\
\hline
\end{tabular}

Table 2: Pre operative conductive hearing loss

\begin{tabular}{cc}
\hline $\mathrm{dB}$ & No. of patients \\
\hline $31-35$ & 0 \\
$36-40$ & 24 \\
$41-45$ & 49 \\
$46-50$ & 20 \\
$51-55$ & 12 \\
\hline Total & 105 \\
\hline
\end{tabular}

Table 3: Hearing improvement after myringoplasty

\begin{tabular}{cc}
\hline $\mathrm{dB}$ & No. of patients \\
\hline $21-30$ & 24 \\
$11-20$ & 54 \\
$1-10$ & 9 \\
0 (no improvement) & 18 \\
\hline Total & 105 \\
\hline
\end{tabular}


Pre operatively the maximum number of patients 49 (47\%), were in the $41-45 \mathrm{~dB}$ hearing loss group, followed by $24(23 \%)$ in the $36-40 \mathrm{~dB}$ group, 20 (19\%) in the $46-50 \mathrm{~dB}$ group and 12 (11\%) in the $51-55 \mathrm{~dB}$ group. (Table 2) However, there were no patients in the $26-30 \mathrm{~dB}$ and $31-$ $35 \mathrm{~dB}$ group. This shows that, the patients become aware of hearing loss when it reaches the level of $35 \mathrm{~dB}$ and onwards after which they seek medical help. But those with hearing loss from $26 \mathrm{~dB}$ to 35 $\mathrm{dB}$ are either not aware of it, or are neglecting it.

Similarly, four weeks after the operation, 54 patients (51\%), had hearing improvement by $11-$ $20 \mathrm{~dB}, 24$ patients (23\%) by $21-30 \mathrm{~dB}, 9$ patients (9\%) by $1-10 \mathrm{~dB}$, and 18 patients (17\%) had no hearing improvement at all. (Table 3) However, none of the patients who underwent surgery had deteriorated hearing level after the surgery. Overall, $83 \%$ of the patients had some degree of hearing improvement out of which $74 \%$ had hearing improvement of more than $10 \mathrm{~dB}$ and $9 \%$ had hearing improvement of less than $10 \mathrm{~dB}$.

\section{Discussion}

Myringoplasty is evolving as a surgical procedure to improve hearing for the last 50 years. With the availability of operating microscope, micro-surgical instruments and rising number of ENT surgeons, this has become the most frequently performed ear surgery to improve hearing during the last 30 years in Nepal. The results appear promising. This study shows an overall hearing improvement in $83 \%$ of the patients, out of which $74 \%$ had hearing improvement of more than $10 \mathrm{~dB}$.
Karela et $\mathrm{al}^{3}$ found an overall hearing improvement in $91.5 \%$, and suggested that myringoplasty is an operation that can improve hearing in many cases irrespective of age, gender, site and size of a person. Makaya et $\mathrm{al}^{4}$ reported a hearing improvement of more than $10 \mathrm{~dB}$ in $62 \%$ patients and less than 10 $\mathrm{dB}$ in $24 \%$ patients which compares favourably with this study. Umapathy et $\mathrm{l}^{5}$ reported a hearing improvement of more than $10 \mathrm{~dB}$ in $72 \%$ of patients, which correlates closely with this study. Similarly, Kakanevatos et $\mathrm{al}^{6}$ reprted an improvement in air conduction thresholds on pure tone audiometry in $69.2 \%$ of patients. Biswas et $\mathrm{al}^{7}$ reported a mean pre and post-operative air conduction threshold of $34 \mathrm{~dB}$ and $24 \mathrm{~dB}$ and found a mean audiological improvement of $10 \mathrm{~dB}$ in 60.78 $\%$ of patients. Ahmed et $\mathrm{al}^{8}$ reported an average air bone decrease of $12.65 \mathrm{~dB}$ with hearing improvement in $98.5 \%$ of patients. Likewise, Kotecha et $\mathrm{al}^{9}$ reported hearing improvement in 67 $\%$ of cases.

In a study carried out in China by She et $\mathrm{al}^{10}$ it was found that the rate of hearing improvement was $57.5 \%$ by underlay technique and $71.9 \%$ by overunder technique. Air-bone gap decreased by $4.9 \mathrm{~dB}$ in the underlay group and by $9.7 \mathrm{~dB}$ in the overunder group. Sethi et al ${ }^{11}$ reported an overall improvement of hearing in $76 \%$ of patients in which $39.4 \%$ had a closure of air-bone gap within 20-30dB, 34.2\% within 10-20 dB and $26.3 \%$ within $0-10 \mathrm{~dB}$. In a study carried out in Spain by Labatut et al, ${ }^{12}$ hearing improvement established as an air-bone gap difference of less than $20 \mathrm{~dB}$ was seen in $56 \%$ of cases. 
The results from several studies carried out by various authors are far from consistent. Still most of the studies show an improvement of more than $10 \mathrm{~dB}$ in more than $70 \%$ of patients, some even exceeding $90 \%$. Controversies exist about the factors which influence hearing improvement after myringoplasty. Yung et $\mathrm{al}^{13}$ stated that big central, central malleolar, posterior central perforations had greater hearing loss. Other factors such as the presence of active mucosal diseases, reduction of ossicular chain mobility by fibrosis and tympanosclerosis could play a role in determining the degree of hearing improvement after myringoplasty. ${ }^{14}$

The cost and duration of the operation is also reasonable. Complications are minimal. Two patients in this study had an excellent hearing improvement of $55 \mathrm{~dB}$ pre operatively to $25 \mathrm{~dB}$ post operatively. Another fact to be mentioned in this study is that, none of the patients had a deteriorated hearing level after the operation.

\section{Conclusion}

In a developing country like Nepal where a large percentage of hearing impairment is mostly due to chronic suppurative otitis media, tubo tympanic type, myringoplasty can benefit a large number of patients by improving hearing. This is a simple, cost effective, and less time consuming surgical procedure which all the patients with the disease should be encouraged to undergo to improve hearing, as it has an excellent hearing improvement rate of more than $80 \%$ with minimal complications.

\section{References}

1. D. F. Austin, M.E. Glassock. Mechanics of hearing, Surgery of the Ear, $4^{\text {th }}$ edition. Philadelphia. Saunders. 1990;297-319.

2. J.L.Sheehy, M.E. Glassock. Tympanic membrane grafting with temporalis fascia. Arch Otol. 1967;86:391402.

3. M. Karela, S. Berry, A. Walkins, et al. Myringoplasty: surgical outcome. European archives of Otorhinolaryngology. 2008;265:1039-42.

4. L.K.Makaya. Myringoplasty results in a district hospital in Botswana. Trop Doct. 2006;36:176-7.

5. N. Umapathy, P.J. Dekker Myringoplasty. Is it worth performing in children. Arch Otolaryngol Head and Neck Surg. 2003;129:1053-55.

6. A. Karkanevatos, S. De, V.R.Srinivas et al. Daycare myringoplasty: five years experience. J Laryngol Otol. 2003;117:763-5.

7. S.S. Biswas, M.A. Hossain, M.M. Alam MM et al. Hearing evalution after myringoplasty. Bangladesh Journal of Otolaryngology. 2010;16:334-8.

8. Z. Ahmed, M.A. Aslam, A. Sharif et al. Over-under myringoplasty. J Coll Physicians Surg Pak. 2005;15:768-70.

9. F. Kotecha, T. Fowler. Myringoplasty: a prospective audit study. Clinical Otolaryngology and Allied Sciences. 1999;24:126-9.

10. W. She, Y. Dai, F. Chen et al. Comparitve evaluation of over-under myringoplasty and underlay myringoplasty for repairing tympanic membrane perforation. Journal of Clinical Otolaryngology, head and neck surgery. 2008;22(10):433-5. 
L.K. Yadav et al, A study of hearing improvement after myringoplasties in Bir Hospital

11. A. Sethi, I. Singh, K. Agarwal, et al. Pneumatisation correlated to myringoplasty and tubal function. Indian Journal of Otolaryngology and head and neck surgery. 2005;57(4):83-6.

12. P.T. Labatut, G.C.Sierra, R.E. Mora et al. Primary myringoplasties. Results after 2 year follow up period. Acta Otorhinolaryngologica Espanola. 2009;60(2):79-83.
13. M.N. Yung Myringoplasty. Hearing gain in relation to perforation site. J Laryngol Otol. 1983;97:11-7.

14. R. P. Mills. Management of chronic suppurative otitis media. Booth JB, Scott-Brown's Otolaryngology $6^{\text {th }}$ edition. Vol.3. Mumbai. Butterworth-Heinemann. 1997;10:1-9. 